to speak, in their wake, may not the first comet have undergone considerable perturbations and internal action, causing the original assembly of particles to separate into two or, perhaps, more portions? We should thus have two comets pursuing the same path, but passing perihelion at different times.

Ephemeris of Planet 1898 DQ. - We give below an ephemeris for Witt's planet for the remainder of this month. The planet is of the I 2 th magnitude, and will be found in the constellation of Aquarius, a little to the north of the stars $\eta$ and $\zeta$ Aquarii.

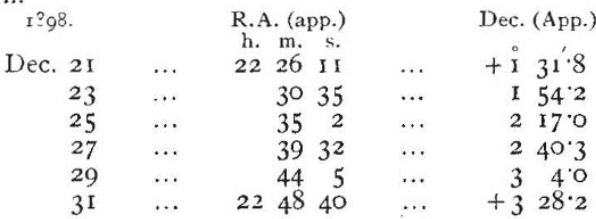

The Companion to the Observatory For $1899 .-$ This handy little vade-mecum, which contains in a condensed form the more useful data that are of more general interest in observational astronomy, has just been issued. As the introduction states, "the present "Companion" closely resembles that of last year," and a brief perusal of its contents does not lead us to state otherwise. Mr. Denning, as usual, is responsible for the meteor notes, and $\mathrm{Mr}$. Maw has supplied numerous observations of double stars. The variable-star ephemerides have been obtained from M. Loewy's " advance. proofs," and Mr. Crommelin has communicated the list of stars which will be occulted by the moon during the lunar eclipse of December 16.

The Solar Disc During 1897.- The solar observatories at Dehra Dun, Mauritius, and Greenwich, give us between then pictures of the disc of the sun 364 days out of the 365 in the year. We have thus practically a daily record of the spots that appear on the solar disc that is absolutely unique in astronomical photography. As we are approaching, as far as we know, a period of minimum sunspots, which, in other words, means a more quiescent state of the solar atmosphere, spots are getting less numerous, and their latitudes are becoming lower. A general summary of an examination of such photographs, as mentioned above, for the year 1897 (Monthly Notices., K'.A.S., vol. lix. No. I), shows that there has been a slight decrease in the daily spotted area as compared with the preceding year, the rapidity of the decline which set in after 1893 having now received a check; the decrease in faculæ has been quite considerable. The most noticeable feature has been the reduction of the mean distance of the spots from the equator. For the four preceding years the distance was $14^{\circ}$, but for 1897 it was not quite $8^{\circ}$. In both hemispheres the decline in latitude has been irregular. In the northern hemisphere the decline was very great for the first six months of the year, and was accompanied with a great decrease in spots. A secondary revival and subsequent decline and revival terminated during the year. A similar but less pronounced movement occurred in the southern hemisphere. The observations of the sun during the current year have shown that the spotted area has begun somewhat to increase again; but whether this is an indication that the minimum is now passed, or that only a temporary revival is taking place, cannot be definitely stated.

The Melbourne Observatory. - The thirty-second report of the Board of Visitors to the observatory, together with the report of the Government astronomer, Mr. P. Baracchi, for the period included between July I, 1897, ard June 30 of the present year, show that the observatory is in good working order. With regard to the position of $\mathrm{Mr}$. Baracchi, the Board says: "We regret to find that the Acting Astronomer still occupies the anomalous position he has occupied since he has had charge of the Observatory; his salary being that which he enjoyed prior to the retirement of $\mathrm{Mr}$ Ellery, and we venture to hope that the Government will soon be able to appoint Mr. Baracchi to the full position of Government Astronomer, with the emolument fixed thereto under the Public Service Act." Mr. Baracchi's report shows that the observatory has been very busy during the past year. The appointment of a new assistant has led to a slight change in the distribution of the work, which has proved advantageous. The meridian work and reduction has been extensive. and the usual time and meteorological service continued. Considerable progress has been made with the astro. NO. I 52 I, VOL. 59] photographic work, the catalogue plates being now complete and the chart plates numbering 278. By an arrangement with Mr. H. C Russell, the Government Astronomer of New South Wales, Mr. Baracchi has decided to have all the work of measuring and reducing the plates of the photographic catalogue of the two zones done at the Melbourne Observatory, the two Colonies sharing the expense. The proposal that four young assistants, directed by one of the officers of the Melbourne Observatory, should be employed on this work, has already been sanctioned, and the work will be commenced as sonn as the appointments have been made. The Victorian Government has placed on the estimates for the current financial year a sum of money for dealing with the observations in terrestrial magnetism at the Melbourne Observatory for the past thirty years. A discussion of such a fine series of observations should be of great value.

\section{THE RELATION OF THE TOXIN AND} ANTI-TOXIN OF SNAKE VENOM.

FARLY in the present year a paper on this subject, by Drs. C. J Martin and Cherry, appeared in the Proceedings of the Royal Society (vol. Ixiii. p. 420). A short summary of their experiments and conclusions was given in these columns. A supplementary paper has just been published by Dr. Martin (Proc. Roj. Soc., vol. lxiv. 88), in which further experiments on this most important subject are detailed. They confirm the conclusions previously arrived at, that the antagonism between the toxins and anti-toxins is a directly chemical one, and is not, as Calmette and others state, due to an interaction solely produced by the agency of the cells of the organism into which these substances enter.

The present experiments were performed with the snake venom derived from the Australian tiger-snake Hoplocephalus (urtus); the anti-venene employed was prepared by Dr. Calmette; and rabbits were selected as the subjects of the experiments. The results obtained are not only of practical importance in the treatment of snake-poisoning, but are of special interest, as they bear on the relations of toxins and antitoxins in general. In snake venom and its antidote we possess substances of which the chemical nature is fairly well understood. A knuwledge of their action (which must be regarded as typical of the whole class of toxins and anti-toxins) furnishes the key to the unlocking of the problem in diphtheria and other diseases, where the chemical investigation of the actual agents is a much more difficult matter, since they are diluted and obscured by the other constituents of the blood and body juices.

Dr. Martin finds that about the same quantity of anti-venene necessary to neutralise the venom in vitro, is capable of doing so also when the former is injected into the blood-stream, and the latter subcutaneously. Solutions of the two substances can be titrated against each other just like standard solutions with the life of a rabbit as an indicator. If anti-venene is introduced into the blood-stream, it is there ready to neutralise the toxin as it is absorbed from the subcutaneous tissues, and the amount found nectssary by titration outside the body is just about adequate to neutralise the toxin as it makes its appearance in the blood. To be quite exact, a slighter proportion of antitoxin is necessary under these circumstances, and this result is no doubt due to delayed chemical action owing to the dilution of the anti-toxin in the blond.

When, however, both venom and anti-venene are introduced into the body subcutaneously, Martin finds, as Fraser originally stated, that at least ten to twenty times the quantity of antivenene must be used to neutralise the toxin. This apparent contradiction of the results first given is really a confirmation of the views of Martin and Cherry. In the first place, it necessitates the inference that anti-toxin is comparatively slowly abiorbed from the subcutaneous tissues. Calmette has stated that the exact contrary is the case, but adduces no experimental proofs of his statement. Brodie's (Joum. of Pathol., 1897) work with the toxin and anti-toxin of diphtheria entirely confirms Martin's experiments with tiger-snake venom.

Our chemical knowledge of toxins and anti-toxins, together with what is known of the physiological mechanism of absorption, is quite in accordance with the view that anti-toxin is only capable of slowly penetrating the capillary wall, whereas the toxin passes through fairly rapidly. The toxins, both in the case of snake poison and diphtheria, are albumoses; they dialyse 
slowly in dialysers constructed of vegetable parchment ; they can be filtered through a gelatin film under pressure; but experiments show they are rapidly absorbed by the blood-vessels. In other words, though their molecules are large, they are not so large as those of the native proteids.

The walls of the capillaries are membranes possessed of permeabilities approximating those of a film of gelatin, and are relatively, although not absolutely, impermeable to proteids (Starling, Journ. of Physiol., vol. xix. p. 311). If molecular size is the obstacle to proteid absorption from subcutaneous spaces, the same would apply to anti-toxins, for these are substances of great molecular size comparable to proteids.

The practical indication of this in the treatment of snake-bite is to inject the anti-venene intravenously, until the potency of the anti-venomous serum which is at the disposal of the public is greatly enhanced.

W. D. H.

\section{REMARKABLE EFFECT OF THE INDIAN EARTHQUAKE OF JUNE I2, I897.}

A REMARKABLE example of the effect of the Indian earthquake of June 12, 1897, upon railway lines is illustrated by a brilliant photo-etching in the general report of the operations of the Survey of India during the years $1896-97$, prepared under the general direction of Major-General C. Strahan, R.E., and recently distributed. The picture (Fig. I), which represents the Manshai Bridge, Cooch Behar State Railway, after the earthquake referred to, is here reproduced in a reduced form.

This earthquake continues to be the theme of discussion by seismologists. One of the most important papers yet publishert is that by Dr. Agamennone in the last Bollettino (vol. iv.. No. 3) of the Italian Seismological Society, of which the following is a summary. At Rome, the early short-period vibrations were first recorded at II.I7 a.m. (G.M.T.), and these lasted until about I I.4O, when the long-period pulsations commenced, reaching a maximum at about $11.47 \frac{1}{2}$. During the first interval there were five distinct maxima, all of which can be identified with those on the records from other observatories. After II. $47 \frac{1}{2}$ these records fail to show marked features in common, and the movement dies away more or less slowly according to the sensitiveness of the instrument employed. At Calcutta, the duration of the earthquake is variously estimated at from four to ten minutes, and at Shillong, which is close to the epicentre, at two minutes. In Europe, the duration of the disturbance, according to magnetograph records, was about half an hour at St. Petersburg, It hours at Wilhelmshaven, and $2 \frac{1}{4}$ hours at Utrecht; and, according to those of different Italian seismometrographs, $I \frac{1}{2}$ hours at Verona, $I^{\frac{3}{4}}$ hours at Rome, 3 hours at Catania, and $3 \frac{1}{4}$ hours at Padua. At Rome, the period of the earliest vibrations was half a second, but this gradually increased to 3.3 seconds after about I 5 minutes. The pulsations which followed had a period of II and Io seconds, in the records of pendulums 16 and 8 metres long, respectively, decreasing to about 8 seconds in both; and it is interesting to notice how closely the different instruments at other observatories agree in this respect. The measures of the maximum tilt of the ground during the passage of the pulsations are less concordant, but the mean of eight good observations in Italy is $12^{\prime \prime} \cdot 4$, a value which agrees fairly well with that of $1 \mathrm{O}^{\prime \prime}$ obtained by means of the bifilar pendulum at Edinburgh. Unfortunately, for the calculations of the velocity, the recorded times at Calcutta differ by $2 \frac{1}{2}$ minutes, being I I. $4 \frac{1}{2}$ (La Touche) and Ir.7 (Oldham). Dr. Agamennone quotes nineteen European records of the time of the first disturbance, and the five best give a mean velocity of 9 or I I $\mathrm{km}$. per second, according to the time adopted for Calcutta. For the long-period pulsations, the corresponding estimates are 2.6 and $2.8 \mathrm{~km}$. per second, i.e. about one-quarter of the above. Lastly, taking the period of the pulsations at Io seconds, the velocity at $2.7 \mathrm{~km}$. per second, and the maximum tilt of the ground at $12^{\prime \prime}$, Dr. Agamennone finds the length of a complete pulsation, as it traversed Italy, to be $54 \mathrm{~km}$., and the height of its crest (or amplitude) about half a metre.

\section{BRITISH ASSOCIATION.}

Conference of the Delegates of the Corresponding Societies.

THE first meeting of the Conference was held at University College, Bristol, on Thursday, September 8 , at 3 p.m. The Corresponding Societies' Committee were represented by Mr. W. Whitaker (Chairman), Dr. Garson, Mr. Hopkinson, Prof. Meldola, Mr. G. J. Symons, and Mr. T. V. Holmes (Secretary).

A short report, which was in the hands of every delegate present, contained the following paragraph :-

The Committee observe with satisfaction that the corresponding societies steadily increase in number, and that the total number of the members composing them also increases. For

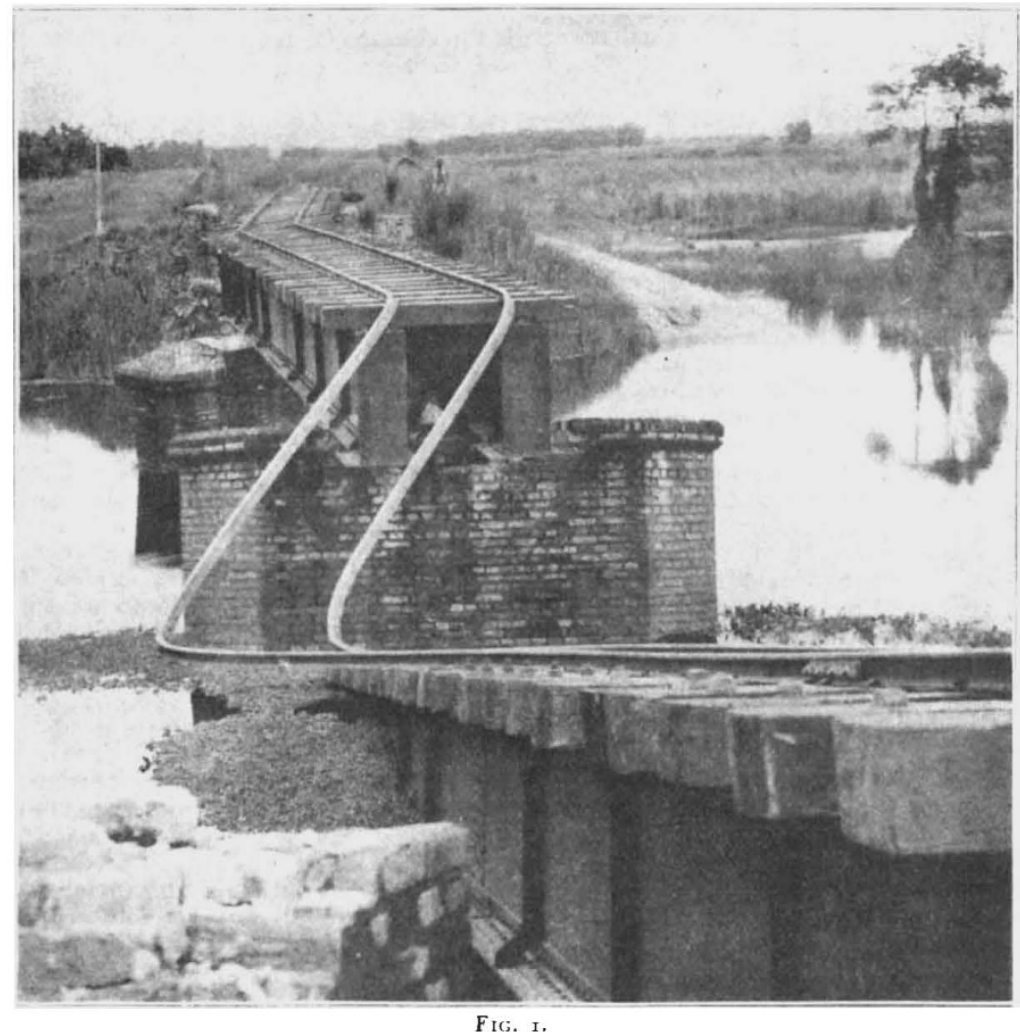
NO. I 52 I, VOL. 50]

example, in the British Association Report o1 the Bath meeling in 1888 there is a list of fifty-five corresponding societies, having a total of 18,950 members. The Toronto Report of last year shows sixty-nine corresponding societies, having a total of 22,395 members. On the other hand, the average number of members in each society appears to have slightly decreased, having been between 344 and 345 in 1888 , and between 324 and 325 in 1897 . But this is accounted for by the collapse of the two federations --the Midland Union and the Cumberland and Westmoreland Association-and the withdrawal of the Royal Scottish Geographical Society between the two periods. For in 1888 these three associations numbered among them 4006 members, as many as would be found in eleven or twelve average societies.

The Committee, while regretting the absence of certain societies whose headquarters are not in London from the list of corresponding societies, add:-Fortunately, in most cases, 